\title{
Localisation of Formyl-Peptide Receptor 2 in the Rat Central Nervous System and Its Role in Axonal and Dendritic Outgrowth
}

\author{
Christabel Fung-Yih Ho ${ }^{1}$. Nadia Binte Ismail ${ }^{1}$. Joled Kong-Ze Koh ${ }^{1}$. Saravanan Gunaseelan ${ }^{2}$-Yi-Hua Low ${ }^{3}$. \\ Yee-Kong $\mathrm{Ng}^{1} \cdot$ John Jia-En Chua ${ }^{2,4,5} \cdot$ Wei-Yi Ong ${ }^{1,5}$
}

Received: 5 April 2018 / Revised: 6 June 2018 / Accepted: 9 June 2018 / Published online: 13 June 2018

(c) The Author(s) 2018

\begin{abstract}
Arachidonic acid and docosahexaenoic acid (DHA) released by the action of phospholipases $\mathrm{A}_{2}\left(\mathrm{PLA}_{2}\right)$ on membrane phospholipids may be metabolized by lipoxygenases to the anti-inflammatory mediators lipoxin A4 (LXA4) and resolvin D1 (RvD1), and these can bind to a common receptor, formyl-peptide receptor 2 (FPR2). The contribution of this receptor to axonal or dendritic outgrowth is unknown. The present study was carried out to elucidate the distribution of FPR2 in the rat $\mathrm{CNS}$ and its role in outgrowth of neuronal processes. FPR2 mRNA expression was greatest in the brainstem, followed by the spinal cord, thalamus/hypothalamus, cerebral neocortex, hippocampus, cerebellum and striatum. The brainstem and spinal cord also contained high levels of FPR2 protein. The cerebral neocortex was moderately immunolabelled for FPR2, with staining mostly present as puncta in the neuropil. Dentate granule neurons and their axons (mossy fibres) in the hippocampus were very densely labelled. The cerebellar cortex was lightly stained, but the deep cerebellar nuclei, inferior olivary nucleus, vestibular nuclei, spinal trigeminal nucleus and dorsal horn of the spinal cord were densely labelled. Electron microscopy of the prefrontal cortex showed FPR2 immunolabel mostly in immature axon terminals or 'pre-terminals', that did not form synapses with dendrites. Treatment of primary hippocampal neurons with the FPR2 inhibitors, PBP10 or WRW4, resulted in reduced lengths of axons and dendrites. The CNS distribution of FPR2 suggests important functions in learning and memory, balance and nociception. This might be due to an effect of FPR2 in mediating arachidonic acid/LXA4 or DHA/ RvD1-induced axonal or dendritic outgrowth.
\end{abstract}

Keywords cPLA2 - iPLA2 - sPLA2 XIIA - PUFA - Omega-3 fatty acid - Arachidonic acid · Docosahexaenoic acid · DHA Lipoxin A4 · Alox5 · Alox $15 \cdot$ Resolvin D1 · LXR receptor · FPR2 · FPRL1 · FPR-L1 - LXA4R · LXA4 receptor · Pain · Cognition $\cdot$ Brain development $\cdot$ Synaptic plasticity $\cdot$ Learning and memory $\cdot$ Neurite $\cdot$ Neurites

John Jia-En Chua

phsjcje@nus.edu.sg

Wei-Yi Ong

wei_yi_ong@nuhs.edu.sg

1 Department of Anatomy, National University of Singapore, Singapore 119260, Singapore

2 Department of Physiology, National University of Singapore, Singapore 119260, Singapore

3 Institute of Neurology, University College London, London, UK

4 Institute of Molecular and Cell Biology, Agency for Science, Technology and Research (A*STAR), Singapore, Singapore 138673

5 Neurobiology and Ageing Research Programme, National University of Singapore, Singapore 117456, Singapore

\section{Introduction}

There has been much recent interest in the role of lipid mediators in neuronal signalling. Fatty acids such as arachidonic acid (AA) or docosahexaenoic acid (DHA) are released from membrane phospholipids by cytosolic phospholipase $\mathrm{A}_{2}\left(\mathrm{CPLA}_{2}\right)$ and calcium-independent phospholipase A2 (iPLA ${ }_{2}$ ) [1], and are subsequently metabolized by 15 -lipoxygenase (15-LOX-1) and 5-lipoxygenase (5-LOX) to produce lipoxin A4 (LXA4) [2] and resolvin D1 (RvD1) [3] or neuroprotectin D1 [4]. Unlike most other metabolites of arachidonic acid, LXA4 is an anti-inflammatory and pro-resolving lipid mediator that facilitates the resolution of inflammation $[5,6]$. It promotes the recruitment of macrophages to clear cellular debris [7, 8], and inhibits macrophage / microglial activation and reduces neuropathic pain [9]. RvD1 is a 
potent pro-resolvin lipid mediator that limits polymorphonuclear leukocyte recruitment to inflammatory loci [10], and neuroprotectin D1 reduces expression of pro-inflammatory factors and protects human retinal pigment epithelial cells from oxidative stress [11]. Both LXA4 and RvD1 activate a G-protein coupled receptor (GPCR), formyl-peptide receptor 2 (FPR2) (also known as FPR-L1) [12]. The latter is a member of the FPR family of seven transmembrane GPCRs originally identified as anti-microbial receptors on the surface of neutrophils and monocytes/macrophages [13].

FPRs mediate cell chemotaxis in a pertussis toxin-sensitive manner, indicating coupling to the Gi (inhibitory) subfamily of $\mathrm{G}$ proteins [13]. The $\mathrm{N}$-formyl group is a crucial determinant of ligand binding to FPR [14]. Since bacterial $[15,16]$ and mitochondrial proteins [17] are the only sources of $\mathrm{N}$-formyl peptides in nature, it widely thought that these receptors mediate trafficking of phagocytes to sites of bacterial invasion or tissue damage [13]. The FPRs are involved in host defence against bacterial infection, and in the clearance of damaged cells [13]. For example, human FPR2 detects bacterial endotoxins including peptides released by Staphylococcus aureus, and specific blocking of FPR2 severely diminished neutrophil detection of endotoxin and leukocyte infiltration [18]. Activation of FPR2 leads to transient calcium ion mobilization [19], ERK phosphorylation [19] and cell motility [20]. Nevertheless, since FPR2 is activated only with high concentrations of $\mathrm{N}$-formyl oligopeptides in the micromolar range in vitro, it is considered a low-affinity receptor for bacterial peptides [21].

FPRs also bind a large and diverse group of lipid and protein ligands with high affinity. For example, FPR2 binds potently to LXA4 in the nanomolar range and is also known as the lipoxin receptor or LXR [12]. Many studies have demonstrated the interaction between FPR2 and LXA4 or RvD1 that mediates the anti-inflammatory, pro-resolving and antinociceptive actions of these lipid mediators [10, 22-26]. FPR2 binds to annexin I (lipocortin I) [27], an endogenous glucocorticoid-regulated protein that has anti-inflammatory activities [28, 29]. The presence of three FPR family members, Fpr1, Fpr-rs1 and Fpr-rs2, has been reported in the hippocampus and hypothalamus of the mouse [30, 31]. A survey of the distribution of FPR2 / FPR-L1 has been carried out at the light microscopic level in human organs, tissues and cells, including the brain, and dense staining was reported, but not illustrated, in the cerebellum and brainstem [32]. Treatment of primary murine microglial cells with lipopolysaccharide results in activation of these cells, and this effect is mediated by FPR [13].

There is much recent interest in the role of lipid mediators as signalling molecules in the brain. In particular, recent findings suggest that lipid anti-inflammatory molecules could have a role in processes such as long term potentiation and memory formation [33-37]. However, the contribution of FPR2 to axonal or dendritic outgrowth is unknown. The present study was carried out, to elucidate the expression and localization of FPR2 at the mRNA, protein, immunohistochemical and ultrastructural level in the rat CNS, and to elucidate its role in axonal or dendritic outgrowth, in primary hippocampal neurons.

\section{Materials and Methods}

\section{Animals}

Adult male Wistar rats (250-300 g) were purchased from the Centre for Animal Resources (CARE), National University of Singapore, and housed in temperature controlled $\left(23 \pm 1{ }^{\circ} \mathrm{C}\right)$, individually ventilated cages on a 12 -h light-dark cycle (7AM-7PM) with access to food and water. Rats were acclimatized for 4 days before the start of experiments. All procedures were in accordance with the Principles of Laboratory Animal Care, and approved by the Institutional Animal Care and Use Committee of the National University of Singapore.

\section{Real-Time Reverse Transcriptase Polymerase Chain Reaction (RT-PCR)}

Four adult male Wistar rats were used for this portion of the study. Rats were deeply anesthetized with a ketamine/xylazine cocktail and sacrificed by decapitation. Ketamine/xylazine mixture used was prepared in saline (ketamine $(75 \mathrm{mg}$ / $\mathrm{kg}$ ), xylazine (10 mg/kg), in $0.9 \%$ sodium chloride solution). Various parts of the rat brain including olfactory bulb, prefrontal cortex, striatum, thalamus/hypothalamus, hippocampus, cerebral cortex (labelled CTX1 and CTX2), cerebellum and brainstem were dissected out. The spinal cord was harvested and sub-divided into the cervical [SC(C)], thoracic $[\mathrm{SC}(\mathrm{T})]$ and lumbar $[\mathrm{SC}(\mathrm{L})]$ segments. CTX1 contained the motor and somatosensory cortices, whereas CTX2 included the parietal association and auditory cortices. Tissues were snap frozen in liquid nitrogen and stored at $-80{ }^{\circ} \mathrm{C}$. Total RNA was extracted using TRizol reagent (Invitrogen, CA, USA) according to manufacturer's protocol. RNeasy® Mini Kit (Qiagen Inc., Hilden, Germany) was used to purify the RNA. Samples were treated with RNase-Free DNase (Qiagen Inc., Hilden, Germany) to remove any contaminating DNA, and reverse transcribed using High Capacity cDNA Reverse Transcription Kits (Applied Biosystems, CA, USA). Reaction conditions were $25^{\circ} \mathrm{C}$ for $10 \mathrm{~min}, 37^{\circ} \mathrm{C}$ for $120 \mathrm{~min}$ and $85^{\circ} \mathrm{C}$ for $5 \mathrm{~s}$. Real-time PCR amplification was performed using 7500 Real time PCR system (Applied Biosystems) on TaqMan ${ }^{\circledR}$ Universal PCR Master Mix (Applied Biosystems), FPR2 (Rn03037051_gH) and $\beta$-actin probes (\#4352340E) (Applied Biosystems, CA, USA) according to 
the manufacturer's instructions. The PCR conditions were: incubation at $50{ }^{\circ} \mathrm{C}$ for $2 \mathrm{~min}$ and $95{ }^{\circ} \mathrm{C}$ for $10 \mathrm{~min}$ followed by 40 cycles of $95{ }^{\circ} \mathrm{C}$ for $15 \mathrm{~s}$ and $60{ }^{\circ} \mathrm{C}$ for $1 \mathrm{~min}$. All reactions were carried out in triplicates. The threshold cycle (CT) was measured as the number of cycles which the reporter fluorescence emission exceeds the pre-set threshold level. Using the $2^{-\Delta \Delta \mathrm{C}_{\mathrm{T}}}$ method, the relative fold changes were quantified by first obtaining the threshold cycle, CT that inversely correlates with the levels of mRNA present in the sample. All reactions were performed in triplicates, and the mean and standard error calculated.

\section{Western Blot Analysis}

Proteins were first extracted from different regions of the brain and spinal cord using T-PER $®$ Tissue Protein Extraction solution containing 1\% HaltTM protease inhibitor and 1\% EDTA solution (Thermo Fisher Scientific, IL, USA). Concentrations of the protein obtained were measured using the Bio-Rad protein assay kit. Protein samples $(30 \mu \mathrm{g})$ were mixed with a loading dye consisting of SDS and DTT, denatured at $95-100{ }^{\circ} \mathrm{C}$ for $10 \mathrm{~min}$ and resolved in $10 \%$ SDS-polyacrylamide (SDS-PAGE) gels under reducing conditions. A protein ladder was used to monitor the electrophoresis run and to check for protein size as well as protein transfer efficacy (Precision Plus Protein Dual Colour Standards, Bio-Rad Laboratories, CA, USA). Resolved proteins were electrotransferred to a polyvinylidene difluoride (PVDF) membrane and non-specific binding sites were blocked by incubation for $1 \mathrm{~h}$ with 5\% non-fat milk in Tris-buffered saline containing $0.1 \%$ Tween-20 (TBST). After blocking, the PVDF membrane was incubated overnight with FPR2 antibody (NLS1878, Novus Biologicals, CO, USA; diluted 1:1000 in 5\% non-fat milk in TBST) at $4{ }^{\circ} \mathrm{C}$. Peptide competition assay was carried out with $5 \times$ protein concentration of the peptide antigen (NLS1878PEP, Novus Biologicals, CO, USA). The PVDF membrane was then washed with TBST and incubated with horseradish peroxidase-conjugated anti-rabbit IgG (Thermo Fisher Scientific, IL, USA; diluted 1:2000 in 5\% non-fat milk in TBST) for $1 \mathrm{~h}$ at room temperature. Protein bands were visualized with an enhanced chemiluminescence kit (Supersignal West Pico, Thermo Fisher Scientific, IL, USA). For loading controls, the membrane was incubated with a stripping buffer for $10 \mathrm{~min}$ at room temperature (Restore Western Blot Stripping Buffer, Thermo Fisher Scientific, IL, USA). The membrane was again blocked with 5\% non-fat milk in TBST before incubating with a mouse monoclonal antibody to beta-actin (SigmaAldrich, MO, USA; diluted 1:10,000 in 5\% non-fat milk in TBST) for $30 \mathrm{~min}$ at room temperature. The membrane was then incubated with horseradish peroxidase-conjugated anti-mouse IgG (Thermo Fisher Scientific, IL, USA; diluted 1:10,000 in 5\% non-fat milk in TBST) for $30 \mathrm{~min}$. The densities of the $38 \mathrm{kDa}$ band corresponding to the predicted molecular weight of FPR2 without posttranslational modifications, were obtained from the different brain regions, and normalized to that of $\beta$-actin, using the Gel-Pro Analyzer3.1 program (Media Cybernetics, MD, USA).

\section{Immunohistochemistry}

Four adult Wistar rats were used for this portion of the study. They were deeply anesthetized and perfused through the left cardiac ventricle with a solution of $4 \%$ paraformaldehyde and $0.1 \%$ glutaraldehyde in $0.1 \mathrm{M}$ phosphate buffer $(\mathrm{pH} 7.4)$. The brains were removed and sectioned coronally at $100 \mu \mathrm{m}$ using a vibrating microtome (Leica, Wetzlar, Germany). The free-floating sections were washed with repeated changes of phosphate-buffered saline (PBS) for $3 \mathrm{~h}$, and incubated overnight with an affinity-purified rabbit polyclonal antibody to FPR2 (NLS1878, Novus Biologicals, CO, USA), diluted 1:500 in PBS. Peptide competition assay was carried out using antigen-absorbed antibody as described above. Sections were incubated for $1 \mathrm{~h}$ in a 1:200 dilution of biotinylated anti-rabbit IgG (Vector, Burlingame, CA), followed by $1 \mathrm{~h}$ incubation with avidin-biotin complex. They were stained for FPR2 using a mixture of 3,3'-diaminobenzidine tetrahydrochloride (Sigma-Aldrich, MO, USA) in nickel-Tris buffered saline containing $0.05 \%$ hydrogen peroxide. Some of the sections were mounted on glass slides and counterstained with methyl green followed by coverslipping. The remaining sections were processed for electron microscopy.

\section{Transmission Electron Microscopy}

Electron microscopy was carried out by subdissecting some of the immunostained sections of the prefrontal cortex into smaller portions. These were post-fixed with $1 \%$ osmium tetroxide, dehydrated in an ascending series of ethanol and acetone, and embedded in Araldite. Thin sections were obtained from the first $5 \mu \mathrm{m}$ of the sections, mounted on copper grids coated with Formvar, and stained with lead citrate. They were viewed using a JEOL 1010 EX electron microscope (JEOL, Tokyo, Japan).

\section{Preparation of Rat Hippocampal Neurons}

Hippocampal neurons were prepared as previously described with modifications [38]. Postnatal (P)0 or P1 MPF HanTac:WH (Wistar) rat pups were decapitated and hippocampi were rapidly isolated from their brains in a neutral (pH 7.3) dissection solution (mGBSS) containing common salts, glucose and HEPES (Sigma) at $4{ }^{\circ} \mathrm{C}$ in $35 \mathrm{~mm}$ diameter dishes. Meninges and dentate gyrus were removed prior to the separation of the hippocampus. Following this, dissected hippocampi were enzymatically digested by $0.25 \%$ 
trypsin (Life Technologies, Carlsbad, USA) in a humidified incubator $\left(37^{\circ} \mathrm{C}, 5 \% \mathrm{CO}_{2}\right)$ for $30 \mathrm{~min}$. Trypsin was removed and hippocampi slices were triturated up and down for ten times with a siliconized 9 in Pasteur pipette consisting of a fire polished tip opening of approximately $0.7-0.9 \mathrm{~mm}$ in diameter. After the hippocampi have settled to the bottom (in about $2 \mathrm{~min}$ ), the supernatant was collected and the remaining sediments were triturated twice more for 10 and 8 times respectively in 5\% serum medium containing MEM Eagle modified (Sigma), glucose, $2 \mathrm{mM}$ glutamine, MEM-vitamin, Mito + Serum extender (Corning, New York, USA) and fetal bovine serum (FBS). The resulting cell suspension was centrifuged at $500 \mathrm{~g}$ for $5 \mathrm{~min}$ and the cell pellet resuspended in neuronal plating media comprising DMEM/F12 Ham's Nutrient Mixture (Sigma), $0.5 \mathrm{mM}$ glutamine and B27 (Life Technologies). Cells were plated on HCl-treated glass coverslips coated with poly-D-lysine at a density of 30,000 cells per 12-well plate or 4,000 cells per 96-well plate.

\section{Cell Viability Assays}

Cytotoxicity profiling was performed in 96-well transparent plates with Alamarblue $\AA$ (Invitrogen $\AA$ ) cell viability reagent. PBP10 and WRW4 were purchased from Tocris Bioscience and diluted in water to obtain 5 and $8 \mathrm{mM}$ stock solutions, respectively. Further dilutions to working concentrations of each compound were achieved by diluting in neuronal plating media. To determine the optimal dosage for each drug, neurons plated in 96-well plates were exposed to a range of concentrations of PBP10 or WRW4 $(1.25-10 \mu \mathrm{M})$ for $24 \mathrm{~h}$. Non-drug treated samples were treated with vehicle control (water). PBS was used to wash each well twice prior to the addition of $100 \mu \mathrm{l}$ of Alamarblue $®$ mixture consisting of $10 \mu$ Alamarblue ${ }^{\circledR}$ reagent and $90 \mu$ of neuronal plating media. After $4 \mathrm{~h}$ of incubation in the dark, fluorescence from individual wells was measured using the TECANTM Reader (Infinite ${ }^{\circledR} 200$ PRO series) employing excitation and emission wavelengths of 570 and $585 \mathrm{~nm}$, respectively.

\section{Axon and Dendrite Growth Assays}

Hippocampal neurons grown 1 day in vitro (DIV) were treated with $5 \mu \mathrm{M}$ of PBP10 or $7.5 \mu \mathrm{M}$ of WRW4 for 3 days. Control samples were treated with vehicle control (water). Cells were fixed with $3.7 \%$ paraformaldehyde (Sigma) at the end of 3 days and permeabilised with $0.3 \%$ Triton-X (Sigma). The fixed samples were then rinsed with PBS and blocked with $10 \%$ normal goat serum (Merck) at room temperature for 30 to $45 \mathrm{~min}$. Cells were incubated with primary antibodies against MAP2 (polyclonal rabbit anti-MAP2, Synaptic Systems, dilution 1:400) and Tau (polyclonal guinea pig anti-Tau, Synaptic Systems, dilution 1:400) at room temperature for $1 \mathrm{~h}$ before three consecutive washes with PBS to remove excess antibodies. Following this, cells were incubated with secondary antibodies (Cy2-conjugated donkey anti-rabbit, dilution 1:200; Cy3-conjugated donkey anti-guinea pig, dilution 1:400; both from Jackson ImmunoResearch) for $1 \mathrm{~h}$ at room temperature. Cells were further washed with PBS prior to mounting onto glass slides with Fluoro-Gel II with DAPI (Electron Microscopy Sciences).

\section{Quantification of Axon and Dendrite Lengths}

Images of individual neurons per treatment (that is, with or without drugs) were acquired and tiled using a Zeiss Axio Observer Z1 Microscope equipped with a motorised stage. Total axon and dendrite lengths were measured using the semiautomatic tracing function in the NeuronJ plugin of ImageJ. Possible differences in neurite lengths between drug-treated (PBP10 or WRW4) and vehicle treated controls, were analysed using one-way ANOVA with Dunnett's post-test using GraphPad Prism 6.0 software. $p<0.05$ was considered significant.

\section{Results}

\section{Expression of FPR2 mRNA in the Rat CNS}

The relative expression levels of FPR 2 mRNA in the brain and spinal cord were determined by real-time RT-PCR (Fig. 1). Results showed that the striatum had the lowest level of FPR2 mRNA expression. Hence all fold changes were normalized to that of the striatum. The brainstem (BS) had the greatest FPR2 mRNA expression level, followed by the spinal cord lumbar [SC(L)], spinal cord cervical [SC(C)], thalamus/hypothalamus (THA), spinal cord thoracic [SC(T)] and prefrontal cortex (PFC). Low levels of FPR2 mRNA were found in the olfactory bulb, hippocampus, cerebellum and striatum (Fig. 1).

\section{Expression of FPR2 Protein in the Rat CNS}

Western blot analysis showed that the FPR2 antibody recognised two major bands and one diffuse band. Blots incubated with antigen-absorbed antibody showed reduced density of the bands, indicating specificity of the antibody (Fig. 2a). The major band of approximately $38 \mathrm{kDa}$ and the diffuse band of $39 \mathrm{kDa}$ represent the non-glycosylated form of FPR2. The other major $55 \mathrm{kDa}$ band is likely a glycosylated form of FPR2. Quantitative densitometric analysis of the $38 \mathrm{kDa}$ band corresponding to the molecular weight of FPR2 without posttranslational modifications, revealed the brainstem had the highest expression, followed by the cervical spinal cord, thalamus/hypothalamus, lumbar spinal cord, cerebellum, primary and secondary motor cortex and 


\section{Expression of FPR2 mRNA in the CNS}

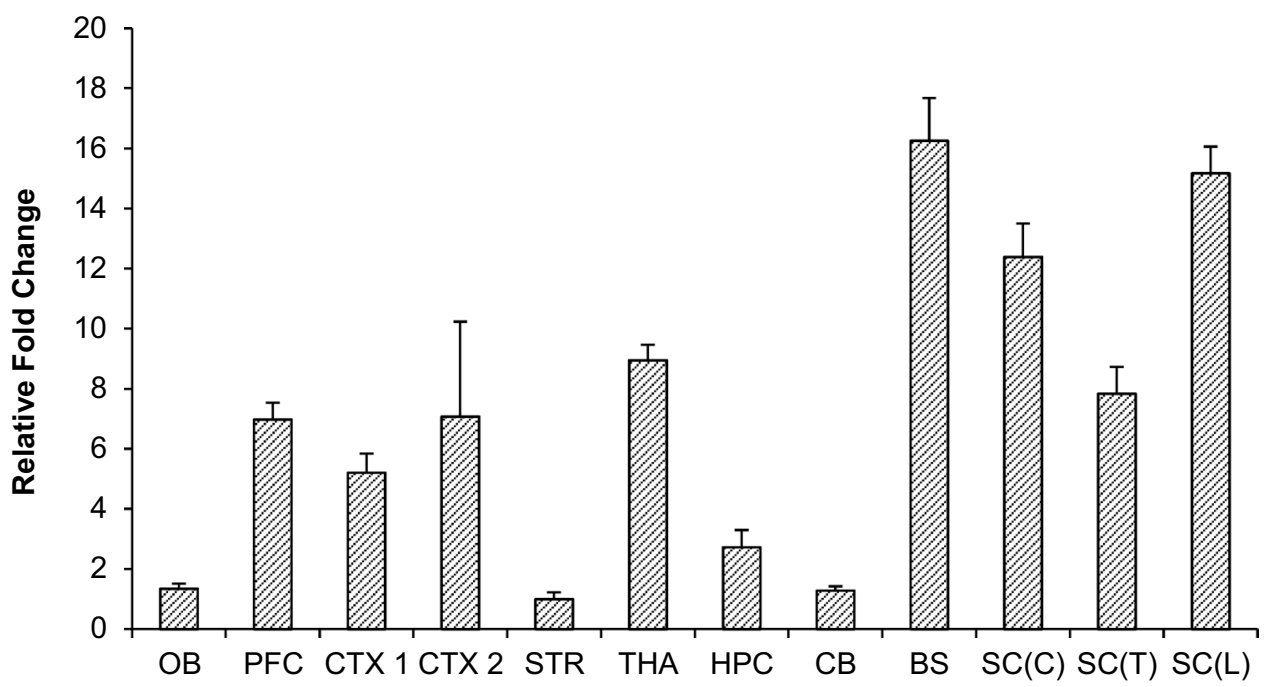

Fig. 1 Real-time RT-PCR analysis of FPR2 mRNA expression in various parts of the rat brain including olfactory bulb (OB), prefrontal cortex (PFC), primary somatosensory cortex (CTX1), parietal association cortex and secondary auditory cortex (CTX2), striatum (STR), thalamus and hypothalamus (THA), hippocampus (HPC), cerebellum
(CB), brainstem (BS), cervical spinal cord [SC(C)], thoracic spinal cord $[\mathrm{SC}(\mathrm{T})]$, and lumbar spinal cord $[\mathrm{SC}(\mathrm{L})]$.Fold change values were normalized to the lowest expressing FPR2 mRNA in the striatum. Data represents mean and standard error from 4 Wistar rats
Fig. 2 a Immunoblot of FPR2 protein in various parts of the rat brain including olfactory bulb (OB), prefrontal cortex (PFC), primary somatosensory cortex (CTX1), parietal association cortex and secondary auditory cortex (CTX2), striatum (STR), thalamus and hypothalamus (THA), hippocampus (HPC), cerebellum (CB), brainstem (BS), cervical spinal cord $[\mathrm{SC}(\mathrm{C})]$, thoracic spinal cord $[\mathrm{SC}(\mathrm{T})]$, and lumbar spinal cord $[\mathrm{SC}(\mathrm{L})]$. Blots incubated with antigen-absorbed antibody i.e. peptide competition, show reduced band intensities. $\mathbf{b}$ Densities of the $38 \mathrm{kDa}$ band corresponding to the molecular weight of FPR2 without posttranslational modifications normalized to that of $\beta$-actin. Data represents mean and standard error from four Wistar rats

\section{OB PFC CTX1 CTX2 STR THA HPC CB BS SC(C) SC(T) SC(L)}

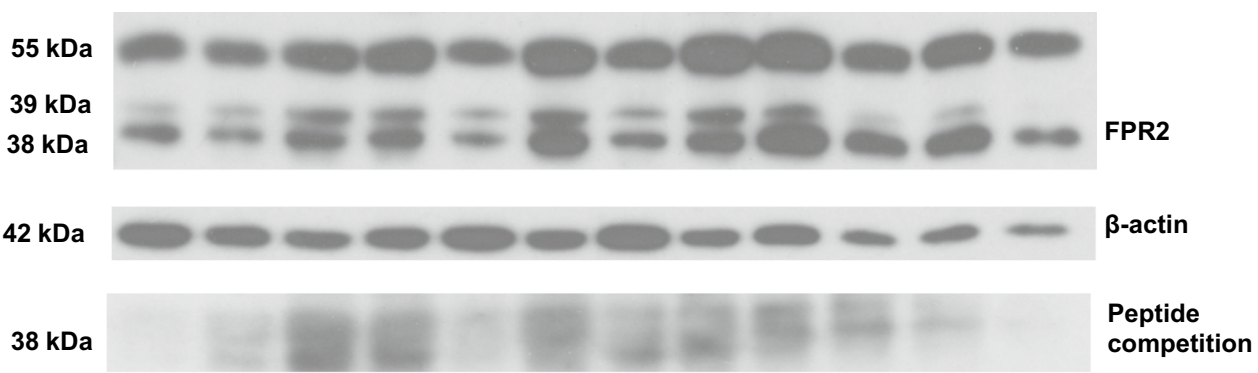

Expression of FPR2 Protein in the Rat CNS

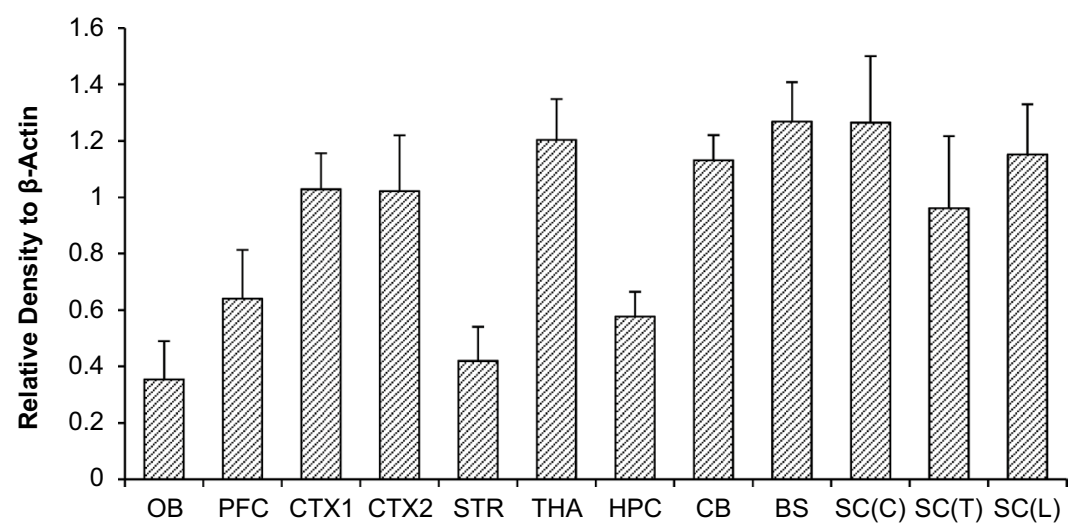

the primary somatosensory cortex (CTX1), parietal association cortex and secondary auditory cortex (CTX2), thoracic spinal cord, prefrontal cortex, hippocampus, striatum and olfactory bulb (Fig. 2b). 


\section{Immunohistochemistry}

Sections incubated with antibody neutralised by the blocking peptide showed absence of immunostaining, indicating specificity of immunoreaction (Fig. 3a). Moderately dense staining was observed in the olfactory bulb (Fig. 3b). The cerebral cortex was moderately labelled (Fig. 3c). Little or no staining was observed in neuronal cell bodies. Instead, staining was observed as punctuate profiles in the neuropil. These were found to be mostly axon pre-terminals at electron microscopy (see below). The hippocampal formation was lightly stained, except for the cell bodies, dendrites, and axons of dentate granule neurons (mossy fibres) which were very densely labelled. The mossy fibres appeared as a


Fig. 3 Sections from the forebrain. a Sections labelled with antigenabsorbed antibody, showed absence of labelling. b Moderately dense staining is present in the olfactory bulb. $\mathbf{c}$ The cerebral cortex (CX) is moderately labelled. Staining is present in punctuate profiles in the neuropil. d The cell bodies, dendrites (DG) and axons (mossy fibres, MF) of dentate granule neurons are densely labelled. e The amygdala (AM) is lightly labelled. f The caudate-putamen (CP) is lightly labelled. The globus pallidus (GP) is very lightly labelled or unlabelled. $\mathbf{g}$ The thalamus is lightly labelled. $\mathbf{h}$ The hypothalamus (HT) is moderately densely labelled. Scale $=0.5 \mathrm{~mm}$ characteristic band in the stratum lucidum of CA3 (Fig. 3d). The amygdala (Fig. 3e) and striatum (Fig. 3f), including the caudate putamen (Fig. 3f) were lightly labelled. As with the cerebral neocortex, label was mostly absent from cell bodies, but present as punctuate profiles in the neuropil. The globus pallidus was very lightly labelled or unlabelled (Fig. 3f). The thalamus was lightly labelled (Fig. 3g), while the hypothalamus was moderately labelled (Fig. 3h). The cerebellar cortex contained scattered labelled Purkinje neurons, but was otherwise unlabelled (Fig. 4a). Dense staining was, however, observed in the deep cerebellar nuclei (Fig. 4b), and nuclei in the brainstem that are connected to the cerebellum, including the inferior olivary nucleus (Fig. 4c) and
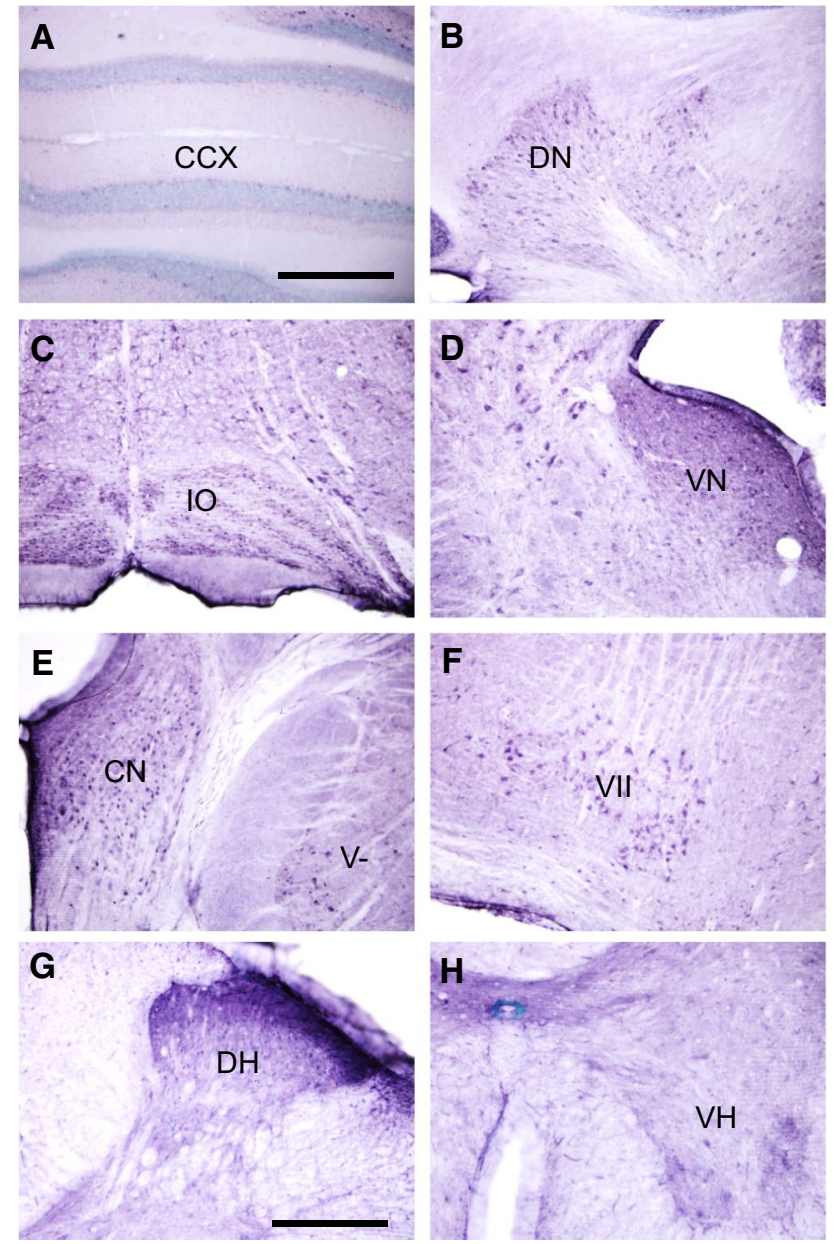

Fig. 4 Sections in the hindbrain and spinal cord. a The cerebellar cortex contained scattered, lightly labelled Purkinje neurons. b Dense staining is present in the deep cerebellar nuclei, including the dentate nucleus (DN). c The inferior olivary nucleus (IO) is densely labelled. d The vestibular nuclei (VN) are densely labelled. e The dorsal and ventral cochlear nuclei $(\mathrm{CN})$, and the spinal trigeminal nucleus (V) are densely labelled. $\mathbf{f}$ The facial motor nucleus (VII) is densely labelled. $\mathbf{g}$ The dorsal horn of the spinal cord (DH) is densely labelled. $\mathbf{h}$ The ventral horn $(\mathrm{VH})$ of the spinal cord is moderately densely labelled. Scale: $\mathbf{a}-\mathbf{f}: 0.5 \mathrm{~mm} . \mathbf{g}, \mathbf{h}=250 \mu \mathrm{m}$ 
vestibular nuclei (Fig. 4d). The dorsal and ventral cochlear nuclei (Fig. 4e), the spinal trigeminal nucleus (Fig. 4e) and the facial motor nucleus (Fig. 4f) were densely labelled. Dense labelling was observed in the superficial portion of the dorsal horn (Fig. 4g), while moderate staining was found in the ventral horn (Fig. 4h) of the spinal cord.

\section{Transmission Electron Microscopy}

Electron microscopy of immunostained sections of the prefrontal cortex showed FPR2 label was mostly present in axon pre-terminals with small round synaptic vesicles that did not form synapses with dendrites (Fig. 5a, b). Occasional labelled axon terminals were observed to form asymmetrical, putatively glutamatergic synapses with unlabelled dendrites (Fig. 5c), and occasional, labelled dendrites were found that formed asymmetrical synapses with unlabelled axon terminals (Fig. 5d). Glial cells and blood vessels were unlabelled.

\section{Inhibition of FPR2 Signalling Reduces Axon and Dendrite Growth}

To examine the possible roles of FPR2 in neurons, we exposed developing hippocampal neurons to the FPR2 inhibitors WRW4 or PBP10. WRW4 is a six amino acid peptide that has been shown to block FPR2 signalling by inhibiting the binding of FPR2 agonists [39]. PBP10 is a ten-amino acid long, membrane permeable peptide derived from gelsolin that inhibits FPR2 signalling by blockade of several FPR2-mediated downstream processes [40, 41]. We postulated that inhibition of FPR2 signalling could affect axonal outgrowth in developing neurons. To determine this, we exposed primary hippocampal neurons to increasing doses of WRW4 or PBP10 to determine the optimal concentration to be used for each drug. We decided to expose the neurons to $5 \mu \mathrm{M}$ (PBP10) and $7.5 \mu \mathrm{M}$ (WRW4) since more than $80 \%$ of the treated neurons remained viable when analysed by the Alamarblue cell viability assay, when the drugs were used at or below these concentrations (Fig. 6a, b). Strikingly, we observed that total axonal length was significantly decreased in drug-treated neurons (Fig. 6c, d). Interestingly, PBP10 appeared to exert a much greater effect than WRW4 $(54.8 \pm 4.7 \%$ vs. $17.2 \pm 3.6 \%$ reduction, respectively). This result is consistent with previous findings that PBP10 negatively impacts actin assembly [40, 42]. Remarkably, neurons exposed to both drugs also demonstrated significant reductions in total dendritic length (Fig. 6e). Importantly, the Alamarblue cell viability assay detects the metabolic activity of a cell based on the oxidation-reduction (REDOX) potentials of molecules involved in the electron transport chain, which takes place in the mitochondria [43]. Given that both mitochondrial function and homeostasis are intact with the dosage used, local demands of ATP supply and calcium buffering capacity are therefore normal. This indicates that the viable cells are still able to grow normally with no effects
Fig. 5 Electron micrographs of FPR2 immunostained sections from the prefrontal cortex. a, b Immunostaining is mostly present in axon pre-terminals (PrT) that did not form synapses with postsynaptic structures. c Occasional axon terminals (AT) are observed to form asymmetrical, putatively glutamatergic synapses (S) with unlabelled dendrites (DE). d Occasional labelled dendrites (DE) are also found, that formed asymmetrical synapses $(\mathrm{S})$ with unlabelled axon terminals (AT). Scale: a, $\mathbf{b}, \mathbf{c}=50 \mathrm{~nm}, \mathbf{e}=100 \mathrm{~nm}$
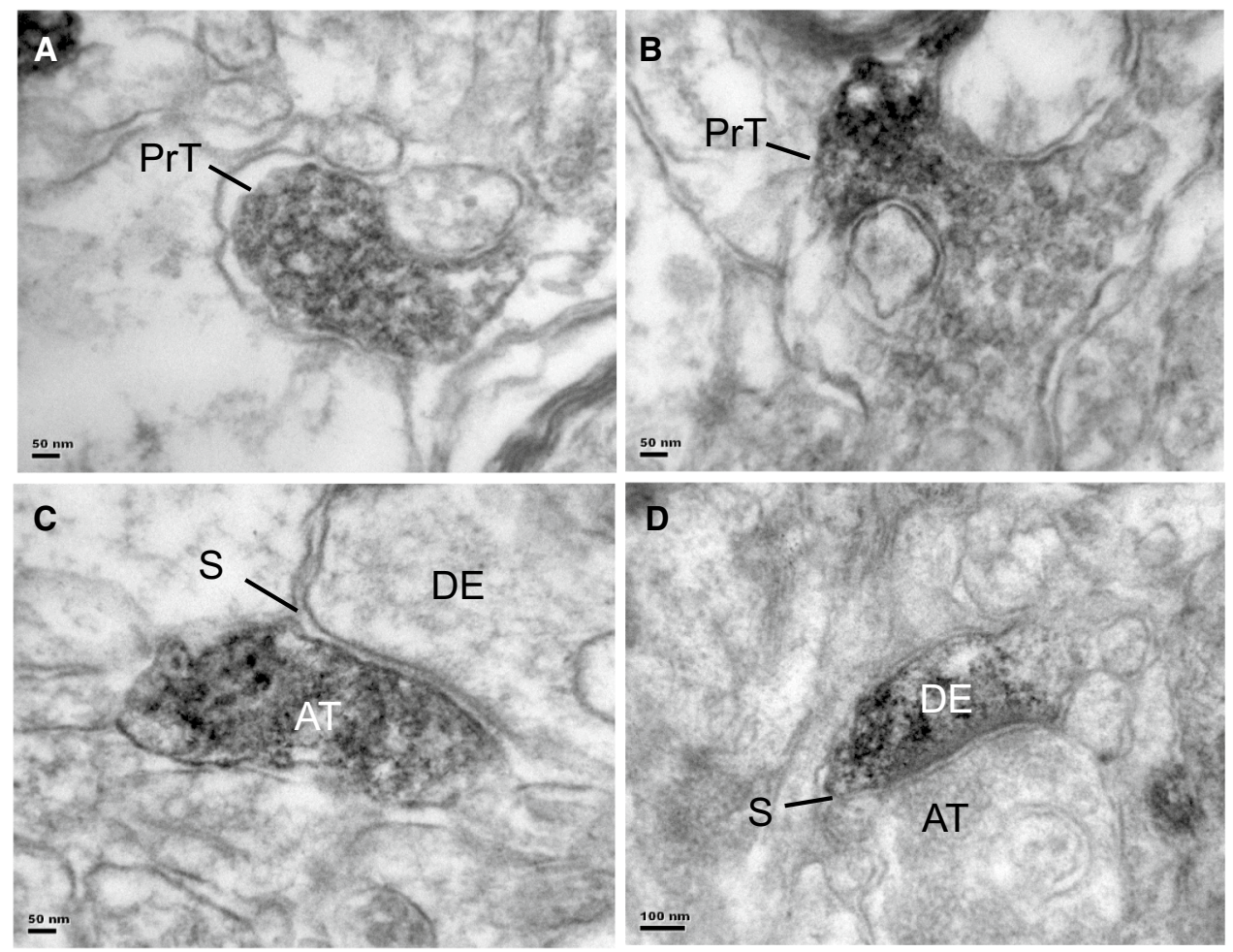

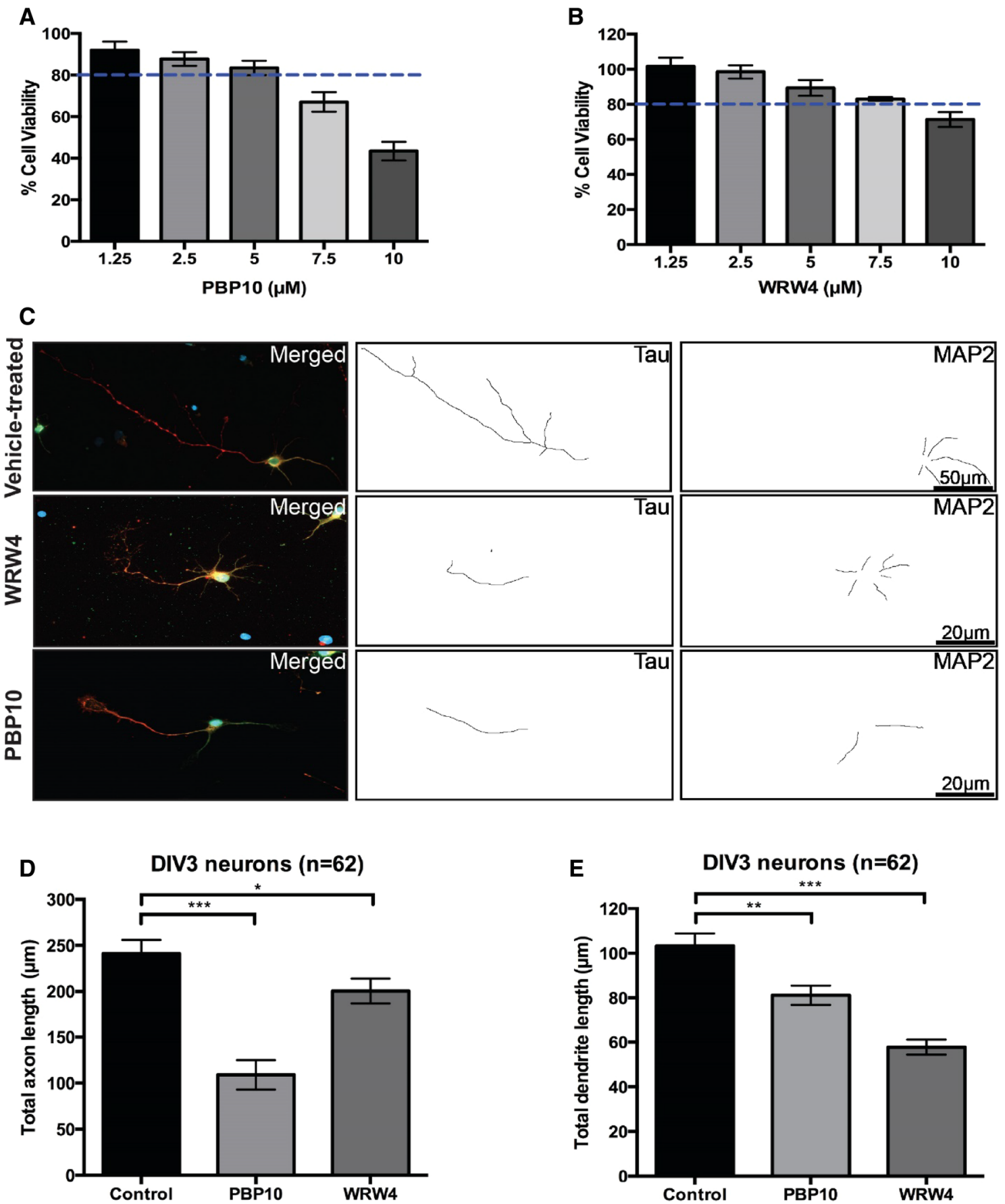

Fig. 6 Treatment with WRW4 and PBP10 negatively affects axon and dendrite outgrowth in developing hippocampal neurons. Hippocampal neurons were exposed to increasing doses of PBP10 (a) or WRW4 (b) a day after plating and cell viability was evaluated 1 day after treatment. Drug concentrations below 5 and $7.5 \mu \mathrm{M}$ showed more than $80 \%$ cell viability (indicated by the blue dotted lines) for PBP10 and WRW4 respectively. c Representative immunofluorescence microscopy images showing Tau (an axonal marker, in red) and MAP2 (a dendritic marker, in green) in drug-treated (PBP10 or WRW4) or vehicle-treated neurons with their respective axon and dendrite traces. Quantitative analyses of mean total dendrite length (d) and mean total axon length (e) in drug- or vehicle-treated neurons. While both WRW4 and PBP10 reduced axonal and total dendritic lengths in comparison to the vehicle-treated control, PBP10 demonstrated a stronger effect in reducing the axon length while WRW4 exhibited a larger influence in decreasing total dendritic length. Data was derived from two independent experiments. Error bars represent SEM. Scale bar in c correspond to $50 \mu \mathrm{m}$. Statistical analyses in panels $\mathbf{d}$ and $\mathbf{e}$ were performed with one-way ANOVA and corrected using Dunnett's post-test. $* * * \mathrm{p}<0.001$; $* * \mathrm{p}<0.01$; and $* \mathrm{p}<0.05$ 
from cell impairments contributing to the reductions in total axonal and dendritic lengths. Thus the reductions in total axonal and dendritic length are directly due to the effects of inhibiting FPR2 signalling when exposed to WRW4 or PBP10. Results are consistent with recent studies which show that FPR2 is expressed in hippocampal neural stem cells, and promotes differentiation into neurons with more and longer primary neurites per cell $[44,45]$.

\section{Discussion}

The present study was carried out to elucidate the expression and distribution of FPR2 in different regions of the brain and spinal cord. Real-time RT-PCR results indicate that FPR2 mRNA is generally present in all brain regions, with higher expression in the brainstem and spinal cord than the forebrain. In particular, expression in the brainstem is double that of the cerebral cortex, and 16 times that of the striatum. The results of Western blots are generally consistent with that of RT-PCR, and high protein expression was found in the brainstem and spinal cord. Several bands were found in Western blots which were all absent/markedly attenuated in blots incubated with antigen-absorbed antibody, indicating specificity of the antibody: two bands of 38 and $39 \mathrm{kDa}$ represent the non-glycosylated form of FPR2. The $38 \mathrm{kDa}$ band is consistent with the expected molecular weight of FPR2, and the diffuse $39 \mathrm{kDa}$ band is also likely a nonglycosylated form of FPR2, while the $55 \mathrm{kDa}$ band is likely a glycosylated form of the receptor. FPR2 is known to be glycosylated [46] and conserved $N$-glycosylation sites are found on the human FPR2 protein at the N-terminus (Asn4) and second extracellular loop (Asn179) [47]. It is likely the rat ortholog possesses these sites as well. A wide range of molecular weights of FPR2 on SDS-PAGE gels has been reported in the literature, ranging from 38 to $100 \mathrm{kDa}$, which is attributed to glycosylation or dimerization [25, 48, 49]. More than a single band of protein is also found in Western blots of FPR1, which is attributed to a mixture of non-glycosylated and differently-glycosylated forms of the receptor $[50,51]$. Glycosylation is necessary for the proper folding of FPR1 [51], and this is likely also for FPR2.

Immunohistochemical analyses showed absence of staining in sections that had been incubated with antigenabsorbed antibody, indicating specificity of immunolabelling. Consistent with the RT-PCR results, generally denser staining was observed in the brainstem and spinal cord than the forebrain. The cerebral cortex was moderately densely immunolabelled for FPR2, and staining was observed as punctuate profiles in the neuropil. The hippocampus was lightly stained, except for dentate granule neurons and their axons (mossy fibres), which were densely labelled. These findings are congruent with studies that show that FPR2 is expressed in hippocampal neural stem cells $[44,45]$. Since the dentate gyrus $->$ CA3 projection is part of a trisynaptic circuit through the hippocampus for consolidation of long term memory [52], this suggests an important role of FPR2 in memory formation. The thalamus was lightly labelled, while the hypothalamus was moderately densely labelled. The latter might account for the high levels of FPR2 mRNA and protein detected in this region by RT-PCR and Western blots. The deep cerebellar nuclei, the inferior olivary nucleus and the vestibular nuclei in the brainstem were densely labelled for FPR2. This suggests that FPR2 could be important in balance and motor coordination. The high level of FPR2 immunoreactivity in the deep cerebellar nuclei, and FPR2 protein in western blots of the cerebellum, could be due to a high level of translation, in view of the low level of mRNA expression in the cerebellum. FRP2 immunolabel was also observed in the spinal trigeminal nucleus and the dorsal horn of the spinal cord, which are sites of termination of primary nociceptive afferents. This suggests a role of FPR2 in the ascending pain pathway. LXA4 has been shown to improve learning and memory after subarachnoid haemorrhage, and these effects were mediated by FPR2 [22]. In addition, protective effects of RvD1 against surgery-induced memory loss have been reported [53]. The findings in this study on the rat CNS are consistent with results of a broad survey of FPR2/FPR-L1 immunolocalization at the light microscopic level in human organs. In that study, dense staining was reported (but not illustrated) in the cerebellar system, including the inferior olivary nucleus, vestibular nuclei, spinal trigeminal nucleus and dorsal horn of the spinal cord [32], reviewed in [54]. Previous studies have shown that $\mathrm{A} \beta$ oligomers accelerates senescence in adult hippocampal neural stem/progenitor cells via FPR2, and effect of LXA4 in reducing A $\beta$ toxicity in the mouse brain $[55,56]$.

In the present study, electron microscopy showed FPR2 immunolabel in axon pre-terminals that did not form synapses with dendrites, but could instead represent growth processes. This was tested by examining the effect of FPR2 inhibition in primary cultured neurons. Incubation of cells with concentrations of FPR2 inhibitors PBP10 or WRW4, that did not cause loss in cell viability, showed that inhibition of FPR2 signalling significantly diminished the lengths of axons (labelled by Tau antibody) and dendrites (labelled by MAP2 antibody), indicating that FPR2 is involved in axonal and dendritic outgrowth. Changes in neuronal polarity were also found (data not shown). These results are consistent with findings that resolvin D1 stimulates neurite outgrowth of primary cultured dorsal root ganglion cells from normal mice [57]. They are also in congruence with studies which show that FPR2 promotes neuronal differentiation, with more and longer primary neurites per cell $[44,45]$. 
The findings of dense FPR2 immunolabelling in the brainstem and cerebellum are consistent with our previous findings that that the enzyme that catalyses the release of arachidonic acid from membrane phospholipids, cytosolic phospholipase $\mathrm{A}_{2}\left(\mathrm{cPLA}_{2}\right)$ is also present at high levels in the hindbrain [58] and spinal cord [59]. Arachidonic acid can be further metabolized by lipoxygenases Alox 5 and Alox 12 to form LXA4 [60]. It is striking that both cPLA 2 and FPR2 are present at high levels in almost the same nuclei in the hindbrain. For example, the deep cerebellar nuclei, dorsal and ventral cochlear nuclei, spinal trigeminal nucleus, and dorsal horn of the spinal cord contain high levels of immunostaining to both $\mathrm{cPLA}_{2}[58,59]$ and FPR2 (this study). These observations suggest that the major ligand of FPR 2 in the normal brainstem and cerebellum is LXA4.

In contrast to the brainstem and spinal cord, the cerebral cortex and hippocampus contain much lower levels of $\mathrm{cPLA}_{2}$ expression [58]. However, another $\mathrm{PLA}_{2}$ isoform that is present at high levels in the cortex, which could also release arachidonic acid for LXA4 formation, is secretory phospholipase $\mathrm{A}_{2}$ XIIA ( SPLA $_{2}$ XIIA) [61]. Lipidomic analyses of the prefrontal cortex after antisense knockdown of sPLA ${ }_{2}$ XIIA reveal changes in phospholipid and lysophospholipid species, which are consistent with a role of this enzyme in the endogenous release of arachidonic acid. Antisense oligonucleotide knockdown of sPLA $_{2}$ XIIA in the prefrontal cortex results in deficits in the attention set shifting task [61].

RvD1 is also a ligand for FPR2. RvD1 interacts with FPR2 [23], and attenuates inflammation and promotes functional recovery after focal brain damage [62]. The enzyme calcium independent phospholipase $\mathrm{A}_{2}\left(\mathrm{iPLA}_{2}\right)$ preferentially releases DHA from brain membrane phospholipids. DHA is metabolized by Alox 15 and Alox 5 to RvD1. Both iPLA 2 [63] and Alox15 [33] are expressed at high levels in the forebrain, including the cerebral cortex. Hence, it is possible that besides LXA4, RvD1 is a ligand for FPR2 in the cerebral cortex.

In conclusion, the present study adds to recent findings that show an important role of anti-inflammatory molecules in neural signalling [33], by demonstrating that a receptor for lipoxin A4 and resolvin D1, FPR2, is present in specific locations in the brain and spinal cord. Further studies are necessary to elucidate the in vivo function of FPR2 in the CNS.

Acknowledgements This study was supported by a grant from the National Medical Research Council of Singapore and the National University Health System. Work in JJEC's lab is supported by a research grant from the Singapore Ministry of Education (T1-2015 April-03).

\section{Compliance with Ethical Standards}

Conflict of interest The authors declare that they have no conflict of interest.

Ethical Approval All applicable International, National, and/or Institutional Guidelines for the care and use of animals were followed.

Open Access This article is distributed under the terms of the Creative Commons Attribution 4.0 International License (http://creativeco mmons.org/licenses/by/4.0/), which permits unrestricted use, distribution, and reproduction in any medium, provided you give appropriate credit to the original author(s) and the source, provide a link to the Creative Commons license, and indicate if changes were made.

\section{References}

1. Strokin M, Sergeeva M, Reiser G (2003) Docosahexaenoic acid and arachidonic acid release in rat brain astrocytes is mediated by two separate isoforms of phospholipase A2 and is differently regulated by cyclic AMP and $\mathrm{Ca}^{2+}$. Br J Pharmacol 139:1014-1022

2. Serhan CN, Hamberg M, Samuelsson B (1984) Lipoxins: novel series of biologically active compounds formed from arachidonic acid in human leukocytes. Proc Natl Acad Sci USA 81:5335-5339

3. Serhan CN, Petasis NA (2011) Resolvins and protectins in inflammation resolution. Chem Rev 111:5922-5943

4. Bazan NG, Musto AE, Knott EJ (2011) Endogenous signaling by omega-3 docosahexaenoic acid-derived mediators sustains homeostatic synaptic and circuitry integrity. Mol Neurobiol 44:216-222

5. Serhan CN, Maddox JF, Petasis NA, Akritopoulou-Zanze I, Papayianni A, Brady HR, Colgan SP, Madara JL (1995) Design of lipoxin A4 stable analogs that block transmigration and adhesion of human neutrophils. Biochemistry 34:14609-14615

6. Fierro IM, Colgan SP, Bernasconi G, Petasis NA, Clish CB, Arita M, Serhan CN (2003) Lipoxin A4 and aspirin-triggered 15-epilipoxin A4 inhibit human neutrophil migration: comparisons between synthetic 15 epimers in chemotaxis and transmigration with microvessel endothelial cells and epithelial cells. J Immunol 170:2688-2694 (Baltimore: 1950)

7. El Kebir D, Jozsef L, Khreiss T, Pan W, Petasis NA, Serhan CN, Filep JG (2007) Aspirin-triggered lipoxins override the apoptosis-delaying action of serum amyloid $\mathrm{A}$ in human neutrophils: a novel mechanism for resolution of inflammation. J Immunol 179:616-622 (Baltimore: 1950)

8. Prieto P, Cuenca J, Traves PG, Fernandez-Velasco M, Martin-Sanz P, Bosca L (2010) Lipoxin A4 impairment of apoptotic signaling in macrophages: implication of the PI3K/Akt and the ERK/Nrf-2 defense pathways. Cell Death Differentiation 17:1179-1188

9. Martini AC, Berta T, Forner S, Chen G, Bento AF, Ji RR, Rae GA (2016) Lipoxin A4 inhibits microglial activation and reduces neuroinflammation and neuropathic pain after spinal cord hemisection. J Neuroinflammation 13:75

10. Norling LV, Dalli J, Flower RJ, Serhan CN, Perretti M (2012) Resolvin D1 limits polymorphonuclear leukocyte recruitment to inflammatory loci: receptor-dependent actions. Arterioscler Thromb Vasc Biol 32:1970-1978

11. Mukherjee PK, Marcheselli VL, Serhan CN, Bazan NG (2004) Neuroprotectin D1: a docosahexaenoic acid-derived docosatriene protects human retinal pigment epithelial cells from oxidative stress. Proc Natl Acad Sci USA 101:8491-8496 
12. Chiang N, Serhan CN, Dahlen SE, Drazen JM, Hay DW, Rovati GE, Shimizu T, Yokomizo T, Brink C (2006) The lipoxin receptor ALX: potent ligand-specific and stereoselective actions in vivo. Pharmacol Rev 58:463-487

13. Cui YH, Le Y, Gong W, Proost P, Van Damme J, Murphy WJ, Wang JM (2002) Bacterial lipopolysaccharide selectively up-regulates the function of the chemotactic peptide receptor formyl peptide receptor 2 in murine microglial cells. J Immunol 168:434-442 (Baltimore: 1950)

14. Schiffmann E, Corcoran BA, Wahl SM (1975) N-formylmethionyl peptides as chemoattractants for leucocytes. Proc Natl Acad Sci USA 72:1059-1062

15. Marasco WA, Phan SH, Krutzsch H, Showell HJ, Feltner DE, Nairn R, Becker EL, Ward PA (1984) Purification and identification of formyl-methionyl-leucyl-phenylalanine as the major peptide neutrophil chemotactic factor produced by Escherichia coli. J Biol Chem 259:5430-5439

16. Schiffmann E, Showell HV, Corcoran BA, Ward PA, Smith E, Becker EL (1975) The isolation and partial characterization of neutrophil chemotactic factors from Escherichia coli. J Immunol 114:1831-1837

17. Carp H (1982) Mitochondrial N-formylmethionyl proteins as chemoattractants for neutrophils. J Exp Med 155:264-275

18. Kretschmer D, Gleske AK, Rautenberg M, Wang R, Koberle M, Bohn E, Schoneberg T, Rabiet MJ, Boulay F, Klebanoff SJ, van Kessel KA, van Strijp JA, Otto M, Peschel A (2010) Human formyl peptide receptor 2 senses highly pathogenic Staphylococcus aureus. Cell Host Microbe 7:463-473

19. He R, Sang H, Ye RD (2003) Serum amyloid A induces IL-8 secretion through a $\mathrm{G}$ protein-coupled receptor, FPRL1/LXA4R. Blood 101:1572-1581

20. Babbin BA, Lee WY, Parkos CA, Winfree LM, Akyildiz A, Perretti M, Nusrat A (2006) Annexin I regulates SKCO-15 cell invasion by signaling through formyl peptide receptors. J Biol Chem 281:19588-19599

21. Prossnitz ER, Ye RD (1997) The N-formyl peptide receptor: a model for the study of chemoattractant receptor structure and function. Pharmacol Ther 74:73-102

22. Guo Z, Hu Q, Xu L, Guo ZN, Ou Y, He Y, Yin C, Sun X, Tang J, Zhang JH (2016) Lipoxin A4 reduces inflammation through formyl peptide receptor 2/p38 MAPK signaling pathway in subarachnoid hemorrhage rats. Stroke 47:490-497

23. Krishnamoorthy S, Recchiuti A, Chiang N, Yacoubian S, Lee CH, Yang R, Petasis NA, Serhan CN (2010) Resolvin D1 binds human phagocytes with evidence for proresolving receptors. Proc Natl Acad Sci USA 107:1660-1665

24. Lee HJ, Park MK, Lee EJ, Lee CH (2013) Resolvin D1 inhibits TGF-beta1-induced epithelial mesenchymal transition of A549 lung cancer cells via lipoxin A4 receptor/formyl peptide receptor 2 and GPR32. Int J Biochem Cell Biol 45:2801-2807

25. Hodges RR, Li D, Shatos MA, Bair JA, Lippestad M, Serhan CN, Dartt DA (2017) Lipoxin A4 activates ALX/FPR2 receptor to regulate conjunctival goblet cell secretion. Mucosal Immunol 10:46-57

26. Vital SA, Becker F, Holloway PM, Russell J, Perretti M, Granger DN, Gavins FN (2016) Formyl-peptide receptor 2/3/ lipoxin A4 receptor regulates neutrophil-platelet aggregation and attenuates cerebral inflammation: impact for therapy in cardiovascular disease. Circulation 133:2169-2179

27. Walther A, Riehemann K, Gerke V (2000) A novel ligand of the formyl peptide receptor: annexin I regulates neutrophil extravasation by interacting with the FPR. Mol cell 5:831-840

28. Hayhoe RP, Kamal AM, Solito E, Flower RJ, Cooper D, Perretti M (2006) Annexin 1 and its bioactive peptide inhibit neutrophil-endothelium interactions under flow: indication of distinct receptor involvement. Blood 107:2123-2130
29. Vago JP, Nogueira CR, Tavares LP, Soriani FM, Lopes F, Russo RC, Pinho V, Teixeira MM, Sousa LP (2012) Annexin A1 modulates natural and glucocorticoid-induced resolution of inflammation by enhancing neutrophil apoptosis. J Leukoc Biol 92:249-258

30. John CD, Sahni V, Mehet D, Morris JF, Christian HC, Perretti M, Flower RJ, Solito E, Buckingham JC (2007) Formyl peptide receptors and the regulation of ACTH secretion: targets for annexin A1, lipoxins, and bacterial peptides. FASEB J 21:1037-1046

31. Sahni V, John CD, Buckingham JC, Solito E (2004) Characterization of formylated peptide receptor expression in murine brain, pituitary and adrenal tissue. In: 195th Meeting of the Society for Endocrinology joint with Diabetes UK and the Growth Factor Group. Endocrine Abstracts, London

32. Becker EL, Forouhar FA, Grunnet ML, Boulay F, Tardif M, Bormann BJ, Sodja D, Ye RD, Woska JR Jr, Murphy PM (1998) Broad immunocytochemical localization of the formylpeptide receptor in human organs, tissues, and cells. Cell Tissue Res 292:129-135

33. Shalini SM, Ho CF, Ng YK, Tong JX, Ong ES, Herr DR, Dawe GS, Ong WY (2018) Distribution of Alox 15 in the rat brain and its role in prefrontal cortical resolvin D1 formation and spatial working memory. Mol Neurobiol 55:1537-1550

34. Hashimoto M, Katakura M, Tanabe Y, Al Mamun A, Inoue T, Hossain S, Arita M, Shido O (2015) n-3 Fatty acids effectively improve the reference memory-related learning ability associated with increased brain docosahexaenoic acid-derived docosanoids in aged rats. Biochim Biophys Acta 1851:203-209

35. Xu JY, Chen C (2015) Endocannabinoids in synaptic plasticity and neuroprotection. Neuroscientist 21:152-168

36. Xu JY, Chen R, Zhang J, Chen C (2010) Endocannabinoids differentially modulate synaptic plasticity in rat hippocampal CA1 pyramidal neurons. PLoS ONE 5:e10306

37. Yang H, Zhang J, Breyer RM, Chen C (2009) Altered hippocampal long-term synaptic plasticity in mice deficient in the PGE2 EP2 receptor. J Neurochem 108:295-304

38. Chua JJ, Butkevich E, Worseck JM, Kittelmann M, Gronborg M, Behrmann E, Stelzl U, Pavlos NJ, Lalowski MM, Eimer S, Wanker EE, Klopfenstein DR, Jahn R (2012) Phosphorylation-regulated axonal dependent transport of syntaxin 1 is mediated by a Kinesin-1 adapter. Proc Natl Acad Sci USA 109:5862-5867

39. Bae YS, Lee HY, Jo EJ, Kim JI, Kang HK, Ye RD, Kwak JY, Ryu SH (2004) Identification of peptides that antagonize formyl peptide receptor-like 1-mediated signaling. J Immunol 173:607-614

40. Cunningham CC, Vegners R, Bucki R, Funaki M, Korde N, Hartwig JH, Stossel TP, Janmey PA (2001) Cell permeant polyphosphoinositide-binding peptides that block cell motility and actin assembly. J Biol Chem 276:43390-43399

41. Forsman H, Andreasson E, Karlsson J, Boulay F, Rabiet MJ, Dahlgren C (2012) Structural characterization and inhibitory profile of formyl peptide receptor 2 selective peptides descending from a PIP2-binding domain of gelsolin. J Immunol 189:629-637

42. Vitriol EA, Zheng JQ (2012) Growth cone travel in space and time: the cellular ensemble of cytoskeleton, adhesion, and membrane. Neuron 73:1068-1081

43. Schreer A, Tinson C, Sherry JP, Schirmer K (2005) Application of Alamar blue/5-carboxyfluorescein diacetate acetoxymethyl ester as a noninvasive cell viability assay in primary hepatocytes from rainbow trout. Anal Biochem 344:76-85

44. Wang G, Zhang L, Chen X, Xue X, Guo Q, Liu M, Zhao J (2016) Formylpeptide receptors promote the migration and differentiation of rat neural stem cells. Sci Rep 6:25946

45. Zhang L, Wang G, Chen X, Xue X, Guo Q, Liu M, Zhao J (2017) Formyl peptide receptors promotes neural differentiation in mouse neural stem cells by ROS generation and regulation of PI3K-AKT signaling. Sci Rep 7:206 
46. Singh D, Qi R, Jordan JL, San Mateo L, Kao CC (2013) The human antimicrobial peptide LL-37, but not the mouse ortholog, mCRAMP, can stimulate signaling by poly(I:C) through a FPRL1dependent pathway. J Biol Chem 288:8258-8268

47. Fiore S, Maddox JF, Perez HD, Serhan CN (1994) Identification of a human cDNA encoding a functional high affinity lipoxin A4 receptor. J Exp Med 180:253-260

48. Cooray SN, Gobbetti T, Montero-Melendez T, McArthur S, Thompson D, Clark AJ, Flower RJ, Perretti M (2013) Ligandspecific conformational change of the G-protein-coupled receptor ALX/FPR2 determines proresolving functional responses. Proc Natl Acad Sci USA 110:18232-18237

49. Gavins FN, Yona S, Kamal AM, Flower RJ, Perretti M (2003) Leukocyte antiadhesive actions of annexin 1: ALXR- and FPRrelated anti-inflammatory mechanisms. Blood 101:4140-4147

50. Schneider EH, Weaver JD, Gaur SS, Tripathi BK, Jesaitis AJ, Zelenka PS, Gao JL, Murphy PM (2012) The leukocyte chemotactic receptor FPR1 is functionally expressed on human lens epithelial cells. J Biol Chem 287:40779-40792

51. Wenzel-Seifert K, Seifert R (2003) Critical role of N-terminal $\mathrm{N}$-glycosylation for proper folding of the human formyl peptide receptor. Biochem Biophys Res Commun 301:693-698

52. Fitzgerald MJT, Gruener G, Mtui E (2011) Clinical neuroanatomy and neuroscience. Saunders, Edinburgh

53. Terrando N, Gomez-Galan M, Yang T, Carlstrom M, Gustavsson D, Harding RE, Lindskog M, Eriksson LI (2013) Aspirintriggered resolvin D1 prevents surgery-induced cognitive decline. FASEB J 27:3564-3571

54. Cattaneo F, Guerra G, Ammendola R (2010) Expression and signaling of formyl-peptide receptors in the brain. Neurochem Res 35:2018-2026

55. Medeiros R, Kitazawa M, Passos GF, Baglietto-Vargas D, Cheng D, Cribbs DH, LaFerla FM (2013) Aspirin-triggered lipoxin A4 stimulates alternative activation of microglia and reduces Alzheimer disease-like pathology in mice. Am J Pathol 182:1780-1789

56. He N, Jin WL, Lok KH, Wang Y, Yin M, Wang ZJ (2013) Amyloid-beta(1-42) oligomer accelerates senescence in adult hippocampal neural stem/progenitor cells via formylpeptide receptor 2. Cell Death Dis 4:e924

57. Shevalye H, Yorek MS, Coppey LJ, Holmes A, Harper MM, Kardon RH, Yorek MA (2015) Effect of enriching the diet with menhaden oil or daily treatment with resolvin D1 on neuropathy in a mouse model of type 2 diabetes. J Neurophysiol 114:199-208

58. Ong WY, Sandhya TL, Horrocks LA, Farooqui AA (1999) Distribution of cytoplasmic phospholipase A2 in the normal rat brain. J Hirnforsch 39:391-400

59. Ong WY, Horrocks LA, Farooqui AA (1999) Immunocytochemical localization of cPLA2 in rat and monkey spinal cord. J Mol Neurosci 12:123-130

60. Romano M, Cianci E, Simiele F, Recchiuti A (2015) Lipoxins and aspirin-triggered lipoxins in resolution of inflammation. Eur J Pharmacol 760:49-63

61. Ee SM, Lo YL, Shui G, Wenk MR, Shin EJ, Kim HC, Ong WY (2014) Distribution of secretory phospholipase A2 XIIA in the brain and its role in lipid metabolism and cognition. Mol Neurobiol 50:60-75

62. Bisicchia E, Sasso V, Catanzaro G, Leuti A, Besharat ZM, Chiacchiarini M, Molinari M, Ferretti E, Viscomi MT, Chiurchiu V (2018) Resolvin D1 halts remote neuroinflammation and improves functional recovery after focal brain damage via ALX/FPR2 receptor-regulated microRNAs. Mol Neurobiol. https://doi. org/10.1007/s12035-018-0889-Z

63. Ong WY, Yeo JF, Ling SF, Farooqui AA (2005) Distribution of calcium-independent phospholipase A2 (iPLA 2) in monkey brain. J Neurocytol 34:447-458 